\section{Optical Properties of Thin Solid Films}

By Dr. O. S. Heavens. Pp. vii +261. (London: Butterworths Scientific Publications; New York : Academic Press, Inc., 1955.) 35s. net.

WITHIN recent years the interest in the field of optical properties of thin solid films has been greatly stimulated and many papers have been published, due largely to the development in the methods of preparing thin films and their examination by optical and electron-microscopic techniques. Consequently, a large amount of information about the nature and behaviour of thin films and their optical properties has become available. Dr. O. $S$. Heavens's book is therefore a timely and welcome addition to the existing literature.

There are seven chapters, including the introduction. The second chapter is devoted to the techniques for the production of films, with special emphasis on the evaporation method which is so commonly employed these days. The next chapter briefly describes the structure of solid films as revealed by electron-optical studies. The fourth chapter is devoted to the calculation of the optical properties of thin films, namely, the reflexion-transmission coefficiènts and phase changes at a single film or as system of layers. This chapter will be specially welcomed by those who are starting work in the field and want to have a connected account for their calculations. In the next two chapters are given a discussion of the methods for the measurement of optical constants and thickness of the film, followed by a general survey of the results obtained. Many interesting applications of thin films in the laboratory and industry are covered in the last chapter.

The subject-matter of the book has been well arranged and is presented in a very clear style. Each chapter is followed by a list of references to the original papers. The book will be of use both to the research worker studying optical properties of thin films and those engaged in industry.

\section{Reagent Chemicals and Standards, with Methods} of Testing and Assaying Them

Also the Preparation and Standardization of Volumetric Solutions and Extensive Tables of Equivalents. By Joseph Rosin. Third edition. Pp. $x+561$. (New York : D. Van Nostrand Company, Inc. ; London : Macmillan and Co., Ltd., 1955.) 70s. net.

THE author of this book, formerly chief chemist and chemical director of Merck and Co., has had considerable experience of the testing of chomical reagents and is an expert in the field. In view of the rapid advances in analytical chemistry during recent years, some forty-five new reagents and solvents have been added to this edition. In each entry the physical properties and standards of the substance are given, and the methods used in testing for impurities and, in many cases, for assay are set out in satisfactory detail. Since the standards are now exacting, sensitive methods involving new reagents are often necessary, and it would be hard to find these in the literature. Some references to recent publications are given.

The book is a valuable storehouse of information which should be available in every chemical laboratory. Manufacturers of chemicals should in particular find it of great service in their laboratories ; but it has a widor fiold of usefulness, since in preparative and research work the purity of the materials is often essential, and the methods of testing for traces of likely impurities should be at hand. In the case of substances used as standards in volumetric analysis, the best methods of assay are given. Indicators and solvents are included.

There seem to be scarcely any inaceuracies in the book, which covers in detail a wide field; but 'dithionate' on p. 413 should be 'dithionite', and the name Kolthoff is given incorrectly on p. 498. This is a sound and informative book which will be welcomed by all chemists. The paper, printing and binding are excellent.

\section{Modern Gas Analysis}

By Paul W. Mullen. (Interscience Manuals.) Pp. ix +354 . (New York: Interscience Publishers, Inc. ; London: Interscience Publishers, Ltd., 1955.) 5.50 dollars.

A BOUT two-thirds of this pocket-sized book are devoted to conventional absorptiometric methods of gas analysis, and the remainder to instrumental methods. It thus provides a wide survey of current practice; but the second part in particular is brief, and more information would be needed for the use of all the techniques described. Space has, however, been used prodigally in other ways, and it seems surprising that, among other examples of the historical approach, five pages should be devoted to the derivation of $P V=n R T$, or that a picture of a Fortin barometer which shows few details should occupy nearly a whole page. Most of the large number of illustrations are of the pictorial type found in catalogues, and some demonstrate little beyond the supplier's name; it would have been preferable to leave more room for the text by reducing the number of illustrations of American equipment and including a higher proportion of diagrams of universal application.

The book is well produced, attractive in appearance and gives a readable account of its subject which may be useful to a non-specialist such as myself; but because- of its abbreviated treatment, it is unlikely to appeal to the gas analyst.

\section{Ambrost}

\section{Parva Naturalia}

By Aristotle. A Revised Text with Introduction and Commentary by Sir David Ross. Pp. xi +354. (Oxford : Clarendon Press ; London : Oxford University Press, 1955.) 40s. net.

r HIS book will be valued by all Aristotelian scholars, and by naturalists interested in the early formulation of their science. Present-day psychologists, too, if they consult it, may find a few surprises. For example, the work contains the oldest general formulation of the laws of association. It is well known that some examples of these laws occur in Plato's "Phrdo", but the originality of Aristotle's concept is the introduction of contrast. A reference of great historical significance is that to 'Aristotle's experiment' (frequently mentioned by philosophers) in which a marblo, if held between the crossed first and second finger of either hand, is 'felt' as two objects. The explanation of the effect is commonly ascribed to our involuntary separation of the contacts as distinct in space.

These are only two of the numerous problems contained in the collection; much else deserves careful thought at the current level of observational technique. It is scarcely necessary to add what a delight the whole volume is--the result of the hand of Sir David Ross upon it.
F. I. G. RAWLINS 